\title{
Trading Puts and CDS on Stocks with Short Sale Ban
}

\author{
Sophie Xiaoyan Ni and Jun Pan*
}

July 22, 2011

\begin{abstract}
We focus on the short sale ban of 2008 to examine the interaction between the price discovery in banned stocks and the trading of options and CDS. Within the sample of banned stocks with exchange traded options, stocks whose put-call ratios are in the top quintile underperform the middle group by $2.13 \%$ and $4.01 \%$ over the next three- and five-day returns, respectively. By contrast, the bottom quintile does not perform differently from the middle group. Within the sample of banned stocks with CDS traded and using their one-day percentage change in CDS spreads as a signal, we find cross-sectional predictability of CDS signal for future stock returns. Again, the predictability is asymmetric, driven mostly by stocks with more positive percentage change in CDS spreads, and therefore more negative information according to the CDS market. Overall, our results confirm that in the presence of short sale ban, it takes time for the negative information contained in either the options market or the CDS market to get incorporated into stock prices.
\end{abstract}

${ }^{*} \mathrm{Ni}$ is from Hong Kong University of Science and Technology (sophieni@ust.hk); Pan is from MIT Sloan School of Management and NBER (junpan@mit.edu). We benefited by the comments from Charles Cao, Neil Pearson, Dragon Tang, Wen-lan Qian, Kuo-chiang Wei, Ken Zhong, and participants at HKUST seminar, Shanghai SAIF 2010 conference, the 21th CFEA held at the University of Maryland and CICF conference 2011.The financial support from a Hong Kong RGC Research Grant (Project \# 642309) is gratefully acknowledged. 


\section{Introduction}

Shortly after the bankruptcy filing of Lehman and the government $\$ 85$ billion bailout of AIG, the Securities and Exchange Commission issued an emergency ban on short sale for all financial stocks on September 19, 2008. While the original motivation for SEC to institute such a ban was to prevent further price disruptions and manage the wide-spread crisis of confidence in financial institutions, its effectiveness is questionable and the unintended consequences were many. ${ }^{1}$

In this paper, we focus on the trading behavior in the options market during the short sale ban (SSB). As long as the cost of options trading is not prohibitively expensive, one could think of buying a put on the SSB stock as an indirect, but open channel, through which any potential negative information about the underlying stock could get in. In other words, although the more direct channel is closed, as long as the door is not completely shut, the information will find its way to securities prices. One interesting implication of this hardly surprising observation is that it allows us to follow the flow of information: from options market to the underlying stock market.

Indeed, our first main result shows that in the presence of short sale ban, it takes time for the negative information expressed in the options market to get incorporated into stock prices. Our analysis focuses on the banned financial stocks with exchange traded options over the 14-day period between September 19 through October 8. ${ }^{2}$ Using data from Chicago Board of Options Exchange and International Securities Exchange, we construct put call ratios from put and call option volumes initiated by non-market maker public buyers to

\footnotetext{
${ }^{1}$ See, for example, the New York Times opinion piece by Arturo Bris on September 29, 2008.

${ }^{2}$ Over this time period, there were additions and removals from the original list, we focus stocks that was banned everyday during the ban.
} 
open new option positions on the SSB stocks. For each of the 14 days, we sort the SSB stocks by their put-call ratios into three groups: the top and the bottom $20 \%$ and the middle $60 \%$. The stocks in the top $20 \%$ group are the ones that options investors express the most negative information, and they are also the most interesting stocks for us to study since short sale ban has the potential to impede the incorporation of negative information into stock prices. We find that during the ban, this top $20 \%$ group underperforms the middle $60 \%$ group by $2.13 \%$ over the next three-day return and by $4.01 \%$ over the next five-day return. The differences are not only economically large, but also statistically significant, even though this test was done over a 14-day window. By contrast, the performance of the bottom $20 \%$ group, which relatively speaking options investors are most positive about, is not economically or statistically different from that of the middle $60 \%$ group. In other words, while short sale ban does impede the incorporation of negative information into stock prices, it does not have an impact on the incorporation of positive information.

By performing our analysis within the group of stocks with the same short sale ban and examine the predictability cross-sectionally within this group, we have perhaps provided one of the cleanest results in the literature to document the effect of short sale prohibition on the incorporation of negative information. The cross-sectional aspect is particularly relevant given the volatile nature of the market at the time. It is, however, useful to perform a few more robustness tests. Matching each banned stock with an unbanned stock that also has exchange traded options, we perform the same analysis on the control stocks over the same the ban and find no predictive result in either the top or the bottom $20 \%$ group. For the SSB stocks, we also perform the same analysis over the periods immediately before and after the short sale ban, and find no result. 
The second main result of our paper focuses on the interaction between credit default swaps and stocks during the short sale ban. Given that CDS is an insurance on the potential default of a firm, it is naturally more sensitive to negative information, making it a good candidate for our analysis. It is, however, difficult to obtain trading information on CDS since it is traded over the counter. Moreover, our CDS sample is markedly smaller than the option sample: there are only 60 banned stocks with active CDS quotes. Nevertheless, our result finds that, in the presence of short sale ban, it takes time for the negative information already incorporated in CDS spreads to get into stock prices.

For each banned stock, we construct its daily percentage change in CDS spreads, and use it as a CDS signal. Cross-sectionally, a firm with more positive change in CDS is the one with more negative information, as far as the CDS market is concerned. Connecting this signal to stocks, we find that over the 14-day short ban period, if the CDS signal of one banned stock is one standard deviation higher than that of another banned stock, this stock on average underperforms the other by $1.29 \%$ over the next two-day return, and $2.69 \%$ over the next five-day return. Moreover, this predictability is asymmetric, driven mostly by stocks with more positive percentage change in CDS. Performing the same analysis over the periods immediately before and after the short sale ban, we do not find predictability. Performing the same analysis on 60 unbanned control stocks with CDS traded, we do not find any predictability, either. In other words, the short sale ban is an important ingredient in generating the CDS predictability, which is consistent with our main result from the options market.

Conceptually, our paper follows the theoretical work of Diamond and Verrecchia (1987), who models effects of short sale on the speed of adjustment to private information of security 
prices. In particular, their model predicts that the effect of short-sales on the impoundment of private information into price is relatively more pronounced in the case of bad news versus good news. When there's short prohibitions that eliminate informed and uninformed investors alike, stock price will incorporate negative information with a delay. ${ }^{3}$ The asymmetric nature of our predictability results, for both options and CDS, are very much a confirmation of their prediction. ${ }^{4}$

The impact of the 2008 short ban has been studied by a number of recent papers. Battalio and Schultz (2010) examine the impact of the ban on equity options. They find no evidence of migration of stock investors to the option market to avoid the ban, but they do find that the option market liquidity is severely affected and synthetic share prices for banned stocks are lower than actual share prices. While our study focuses on the relative information efficiency of stock and option markets during the ban. Consistent with no migration during the ban, we also find that the put call ratio of the banned stocks decreased during the ban. Boehmer, Jones, and Zhang (2009) find that banned stocks suffered a severe degradation in quality, as measured by spreads, price impacts and intraday volatility. Kolasinski, Reed, and Thornock (2009) find that the ban increases the informativeness of short sales especially for stocks with listed options. Gagnon and Witmer (2009) document price differences between the U.S. and Canadian shares and trading volume migrations from U.S to Canada among banking stocks during the ban. Harris, Namvar, and Phillips (2009) use a factor-analytic model to show that the ban led to substantial price inflation in the SSB stocks.

\footnotetext{
${ }^{3}$ Their model also shows that when there's short restrictions that drive out more uninformed traders than informed traders, stock price will adjust negative information more efficiently.

${ }^{4} \mathrm{It}$ is, however, important to point out that the information that are used to gauge the speed of adjustment is in fact publicly available: both the put-call ratio and the CDS prices can be obtained in real time with a fee.
} 
Our paper is also related to Sorescu (2000), Danielsen and Sorescu (2001), and Mayhew and Mihov (2005), who focus on option introductions and investigate whether options help to relax binding short sale constraints. Ofek, Richardson, and Whitelaw (2004) find that violations of put-call parity is asymmetric in the direction of short sale constraints, and their magnitudes are strongly related to the cost of short sale. Given that option introductions and cost of short sale are generally endogenous, it is difficult to learn conclusively about how the presence of options market or cost of short sale might affect the underlying stock market. Our paper takes advantage of an event that was also highly endogenous, but this event was imposed on a broad enough set of stocks for us to examine the cross-sectional difference among the SSB stocks.

Our paper is also related to the growing body of literature that examine the cross-market information transmission between stocks and options. Among others, Easley, O'Hara, and Srinivas (1998) provide a formal framework to examine this issue and Pan and Poteshman (2006) present strong evidence that option trading volume contains information about future stock prices. Their result indicates that this information transmission is present during normal times and the predictability is symmetric with respect to positive and negative information. ${ }^{5}$ We focus instead on the short sale ban, and our predictability is asymmetric with respect to the nature of information: the predictability is present only for negative information, but not for positive information.

In contrast, the literature have no conclusive evidence about how information is trans-

\footnotetext{
${ }^{5}$ One important ingredient of their result is that the option volume information used in their analysis was not publicly available during their sample period. More recently and after the publication of their paper, however, the CBOE started to release such information in real time, and the predictability has decreased markedly. For example, during our very short, but special sample period, we do not find any predictability of put-call ratio for unbanned stocks.
} 
mitted between stock and CDS markets. Longstaff, Mithal, and Neis (2005) document that there's no lead lag relation between CDS spread and stock prices. Acharya and Johnson (2007) find a negative cross-correlation between CDS changes and future stock returns for entities with credit deterioration and high CDS levels. Absent these conditions, they show there is no incremental information in CDS market. In more recent study, Norden and Weber (2009) and Tang and Yan (2011) document stock prices lead CDS spread changes in daily frequency. While in monthly frequency, Han and Zhou (2010) find term structure of CDS is associated with future stock returns.

Finally, our paper is related to studies examining the effect of short sale prohibition or restrictions on the stock prices. Bri, Goetzmann, and Zhu (2007) find some evidence that prices incorporate negative information faster in countries where short sales are allowed and practiced. Chang, Cheng, and Yu (2007) analyze the price effects following the addition of stocks to the short list in Hong Kong market, and find that short sale prohibitions tend to cause stock over-valuation. However the decision for a stock to be added on a short list may result from a certain degree of endogeneity. For the studies on short sale restriction, Miller (1977) and Chen, Hong, and Stein (2002) model that stock prices tend to be upward-biased, while Diamond and Verrecchia (1987) model that price will be more efficient especially for negative information. The literature use either short interest or rebate rate as a proxy and document that there's a negative relation between short restrictions and subsequent stock returns. ${ }^{6}$ In addressing the endogenous issue between short restrictions and negative information, the literature conclude that it is the information that drives the negative relation

\footnotetext{
${ }^{6}$ Asquith and Meulbroek (1996),Aitken, Frino, McCorry, and Swan (1998), and Desai, Ramesh, Thiagarajan, and Balachandran (2002) use short interest as a proxy. Jones and Lamont (2002),Geczy, Musto, and Reed (2002), and DAvolio (2002) examine the predictability of rebate rate.
} 
between short restrictions and negative returns. ${ }^{7}$ Our paper, instead, takes advantage of the short sale ban to disentangle the negative information from short sale prohibition, and provides clear evidence that the ban itself slows down the stock price adjustment to negative information.

The rest of the paper is organized as follows. Section 2 provides some details on the short sale ban and the option and CDS data used in our analysis. Section 3 presents our main result with respect to option trading and future stock returns, and Section 4 presents the result relating CDS to future stock returns. Section 5 concludes.

\section{Short Sale Ban, Data and Summary Statistics}

\subsection{Short Sale Ban}

On September 19, 2008, the SEC issued a short sale ban (SSB) on financial stocks. Initially, the ban covered 797 financial stocks selected by the SEC. On the following trading day September 22, the SEC allowed exchanges to determine which firms would be included or excluded from the ban. Eventually, around 990 stocks were elected to be covered by the ban, with some stocks entering and exiting the ban list.

The ban was set to expire in 10 days, but could be extended to 30 days at the SEC's discretion. On October 2, at the end of the initial 10-day effective period, the SEC extended the ban to the earlier of October 17 or three business days following the $\$ 700$ billion financial rescue legislation was passed into law. On October 3, immediately after the rescue plan

\footnotetext{
${ }^{7}$ Boehmer, Jones, and Zhang (2008), Boehmer, Jordan, and Huszar (2010), Diether, Lee, and Werner (2009), etc.
} 
passed the Congress, the SEC announced that the ban would expire at 11:59pm ET October 8. The ban lasts 14 trading days from September 19 to October 8. We choose August 19 to September 18 as the pre-ban period, and October 9 to November 8 as the post-ban period. Both pre- and post- ban periods cover one month.

\subsection{Option Data}

The data used to compute main option trading activity are obtained from CBOE and ISE. The dataset contains daily non-market maker public customer volume for all CBOE and ISE listed options. For each option, the daily trading volume is divided into four types of trades: open buy, in which non-market markers buy options to open new positions; close buy, in which non-market makers buy options to close existing written option positions; open sell, in which non-market makers sell options to open new short positions; and close sell, in which non-market makers sell options to close out existing long options positions. Among these four types of option trades, the information content of the open-buy volume is perhaps the highest given that it does not involve any pre-existing option positions or margin requirements. For this reason, our main analysis will focus mostly on option volumes associated with open buy originated by by public customers. In our analysis, we also use general option volumes obtained from Option Metrics.

During the SSB period, there are 229 banned stocks and 2036 non-banned stocks with options traded on CBOE and ISE. For comparison, we match each optionable SSB stock with an optionable control stock, which is selected by minimizing the sum of the squared percentage differences of stock market capitalization, stock volume, and stock price. The 
matching is done for the period from August 19 to November 8 and no control stock is used twice.

Table 1: Summary Statistics of Stocks with Options

\begin{tabular}{|c|c|c|c|c|c|c|}
\hline & \multicolumn{3}{|c|}{ SSB Stocks } & \multicolumn{3}{|c|}{ Control Stocks } \\
\hline & mean & median & std & mean & median & std \\
\hline \multicolumn{7}{|c|}{ Panel A: Ban Period, Sept 19 - Oct 8} \\
\hline Open Buy $\mathrm{P} / \mathrm{P}+\mathrm{C}(P C)$ & 0.471 & 0.451 & 0.369 & 0.435 & 0.390 & 0.366 \\
\hline Put Volume (contracts) & 713,464 & 71,368 & $2,299,883$ & 607,386 & 60,804 & $1,955,880$ \\
\hline Call Volume (contracts) & 779,988 & 66,850 & $2,602,779$ & 642,717 & 76,757 & $1,944,299$ \\
\hline Option/Stock Volume & 0.128 & 0.069 & 0.204 & 0.122 & 0.062 & 0.200 \\
\hline Put/Stock Volume & 0.068 & 0.031 & 0.138 & 0.058 & 0.023 & 0.128 \\
\hline Call/Stock Volume & 0.060 & 0.033 & 0.097 & 0.064 & 0.032 & 0.103 \\
\hline \multicolumn{7}{|c|}{ Panel B: Before Ban Aug $19-$ Sept 18} \\
\hline Open Buy $\mathrm{P} / \mathrm{P}+\mathrm{C}(P C)$ & 0.500 & 0.506 & 0.362 & 0.417 & 0.362 & 0.367 \\
\hline Put Volume ( contracts) & 972,510 & 84,708 & $3,372,184$ & 658,505 & 62,092 & $2,009,665$ \\
\hline Call Volume (contracts) & 809,980 & 87,708 & $3,015,430$ & 712,102 & 73,912 & $2,186,903$ \\
\hline Option/Stock Volume & 0.112 & 0.058 & 0.159 & 0.132 & 0.063 & 0.220 \\
\hline Put/Stock Volume & 0.058 & 0.024 & 0.090 & 0.058 & 0.023 & 0.105 \\
\hline Call/Stock Volume & 0.054 & 0.027 & 0.089 & 0.074 & 0.032 & 0.144 \\
\hline \multicolumn{7}{|c|}{ Panel C: After Ban Oct 9 - Nov 8} \\
\hline Open Buy $\mathrm{P} / \mathrm{P}+\mathrm{C}(P C)$ & 0.478 & 0.455 & 0.365 & 0.421 & 0.372 & 0.360 \\
\hline Put Volume & 733,014 & 76,193 & $2,201,612$ & 668,849 & 69,368 & $2,072,386$ \\
\hline Call Volume & 658,743 & 87,571 & $1,904,772$ & 606,150 & 83,729 & $1,898,124$ \\
\hline Option/Stock Volume & 0.107 & 0.054 & 0.160 & 0.108 & 0.057 & 0.164 \\
\hline Put/Stock Volume & 0.059 & 0.022 & 0.113 & 0.052 & 0.022 & 0.098 \\
\hline Call/Stock Volume & 0.048 & 0.027 & 0.068 & 0.056 & 0.029 & 0.093 \\
\hline
\end{tabular}

Reported are the time-series averages of daily cross-sectional mean, median, and standard deviation. Open Buy $\mathrm{P} / \mathrm{P}+\mathrm{C}$ is the number of put open buy contracts initiated by public investors divided by open buy put plus call contracts of same trade type. Option/Stock Volume is 100 times the number of option contracts divided by stock volume. Call/Stock Volume and Put/Stock Volume are similar variables for call and put contracts.

Table 1 summarizes the option trading activities of the SSB and control stocks before, during, and after the short sale ban. For each variable, we compute the cross-sectional mean, median and standard deviation for every trading day and report their time series averages. In our main analysis, we use put-call ratio (PC) as information signal in option market. The PC is measured as the number of put contracts open bought by public investors divided by 
the sum of put and call contracts of same trade type. We can see an decreased activity in open bought put relative to call for the SSB stocks during the ban. This can be seen in two ways. First, PC of the SSB stocks is lower during the ban than before and after the ban in both mean and median. Second, the difference between PC of SSB and control stocks is also lower during the ban. This result is consistent with the finding of Battalio and Schultz (2010) that there's no migration of trading from stock to option market during the ban.

Table 1 also reports the summary statistics of general option volume, which also show that the trading in the option market dose not increase during the ban. Though SSB stocks have higher option volumes than control stocks during the ban, option volumes of SSB stocks during the ban are slightly lower than those before the ban, and the decrease is more obvious for put than call options. The option/stock volume of the SSB stocks is slightly higher during the ban period than the non-ban period. Based on the result that the call and put volume do not increase during the ban, the enhanced relative option volume should come from decreased stock volume. Table 1 that the high relative option to stock volume comes from both put and call options.

\subsection{CDS Data}

The CDS data used in this paper are from CMA via Datastream. During the short ban period, there are 395 stocks with CDS daily closing quotes, among which 60 are SSB stocks and 335 are non-SSB stocks. We select 60 control stocks from the 335 non-SSB stocks using the same matching method as before. In particular, control stocks are selected by matching stock market capitalization, stock trading volume and stock price. 
Table 2: Summary Statistics of SSB and Control Stocks with CDS

\begin{tabular}{|c|c|c|c|c|c|c|}
\hline & mean & $\begin{array}{c}\text { SSB } \\
\text { median }\end{array}$ & std & mean & $\begin{array}{l}\text { Control } \\
\text { median }\end{array}$ & std \\
\hline \multicolumn{7}{|c|}{ Panel A: Ban Period, Sept 19 - Oct 8} \\
\hline CDS Spread (bp) & 629.63 & 198.86 & 950.54 & 452.91 & 179.86 & 679.55 \\
\hline CDS Daily Change (bp) & 20.99 & 0.79 & 135.80 & 15.43 & 2.29 & 91.40 \\
\hline CDS Daily Percentage Change (\%) & 1.21 & 0.54 & 11.17 & 2.30 & 1.52 & 6.43 \\
\hline \multicolumn{7}{|c|}{ Panel B: Before Ban, Aug 19 - Sept 18} \\
\hline CDS Spread (bp) & 442.50 & 150.84 & 762.53 & 361.02 & 157.20 & 545.55 \\
\hline CDS Daily Change (bp) & 7.73 & 0.79 & 125.66 & -1.21 & 0.58 & 35.41 \\
\hline CDS Daily Percentage Change (\%) & 1.36 & 0.61 & 10.70 & 0.56 & 0.54 & 5.00 \\
\hline \multicolumn{7}{|c|}{ Panel C: After Ban, Oct 9 - Nov 8} \\
\hline CDS Spread (bp) & 916.12 & 248.40 & 1404.23 & 866.60 & 342.64 & 1281.19 \\
\hline CDS Daily Change (bp) & 10.09 & 2.20 & 161.04 & 32.87 & 4.67 & 240.25 \\
\hline CDS Daily Percentage Change (\%) & 0.56 & 0.99 & 10.61 & 2.87 & 1.90 & 9.15 \\
\hline
\end{tabular}

Reported are the time-series averages of cross-sectional mean, median, and standard deviation.

Table 2 summarizes the CDS data during, before and after the ban. During the ban, the SSB stocks on average have higher CDS spread than the control stocks, and this is reflected in both the cross-sectional mean and median. For example, the average CDS spread was 629.63 bps for the SSB stocks, compared with that of 452.91 bps for the control stocks. Before and after the ban, however, this relation is somewhat mixed, depending on whether mean or median is used in the comparison. We also find that the SSB sample is more dispersed with a higher cross-sectional standard deviation. Overall, there is a general pattern of increasing CDS spreads for both the SSB and control stocks over the sample period as the broad economic condition worsens during our sample period. 


\section{Option trading and future stock returns}

\subsection{Main Results}

In this section we use option signal to investigate whether short sale prohibition reduces the speed of stock price adjustment to negative information. During the ban, investors in option market can still purchase puts to bet on stock price declining. If option trading contains information and stock prices incorporate negative information with a delay, we expect option signal with negative information will have stronger predictability for future stock returns than option signal with positive information. Our main empirical investigation is to test this asymmetric predictability for the SSB stocks during the SSB period. Moreover, we expect this particular predictability to be less obvious for control stocks during the ban or the SSB stocks during non-ban periods.

The option signal we use is the put call ratio $(\mathrm{PC})$ calculated as:

$$
P C_{t}^{i}=P_{t}^{i} /\left(P_{t}^{i}+C_{t}^{i}\right)
$$

where $P_{t}^{i}$ is the number of non-market maker public investor open purchased put contracts for stock $i$ on date $t$, and $C_{t}^{i}$ is the same number for call. Pan and Poteshman (2006) document that this option signal contains information about future stock returns. Follow them, in main analyses, we select sample stocks with at least 50 contracts of open purchased volume in main analyses.

Table 3 reports future five day returns of portfolios sorted on put call ratios. We sort stocks into quintiles based on their open buy put call ratios (PC) for every trading day, then 
Table 3: Returns of Stock Quintiles Sorted on Open Buy Put/Call Ratios (PC)

\begin{tabular}{|c|c|c|c|c|c|c|c|c|}
\hline & Raw. E & Raw. V & Ex. E & Ex. V & Raw. E & Raw. V & Ex. E & Ex. V \\
\hline & \multicolumn{4}{|c|}{ SSB during the ban } & \multicolumn{4}{|c|}{ Control during the ban } \\
\hline Low PC & -1406.94 & -1416.47 & 322.99 & 317.10 & -1264.29 & -1259.84 & 356.03 & 7.11 \\
\hline 2 & -1235.37 & -1269.52 & 310.07 & 285.21 & -1318.03 & -1353.93 & 337.14 & 115.41 \\
\hline 3 & -1296.72 & -1290.28 & 371.25 & 283.63 & -1291.93 & -1225.43 & 271.21 & 322.04 \\
\hline 4 & -1517.00 & -1369.89 & 347.98 & 259.29 & -1126.31 & -1112.25 & 400.19 & 192.51 \\
\hline High PC & -1698.00 & -1722.08 & -10.37 & 25.32 & -1247.07 & -1285.22 & 338.33 & 237.84 \\
\hline $\begin{array}{c}3-\mathrm{L} \\
t \\
\mathrm{H}-3 \\
t\end{array}$ & $\begin{array}{c}110.23 \\
(1.06) \\
-401.29^{* *} \\
(-4.45)\end{array}$ & $\begin{array}{c}126.19 \\
(0.99) \\
-431.80^{* *} \\
(-5.08)\end{array}$ & $\begin{array}{c}48.26 \\
(0.63) \\
-481.62^{* *} \\
(-4.35)\end{array}$ & $\begin{array}{c}-33.47 \\
(-0.53) \\
-258.31^{* *} \\
(-2.42)\end{array}$ & $\begin{array}{c}-27.64 \\
(-0.36) \\
44.86 \\
(0.82)\end{array}$ & $\begin{array}{l}34.41 \\
(0.38) \\
-59.79 \\
(-0.79)\end{array}$ & $\begin{array}{c}-84.82 \\
(-1.06) \\
67.12 \\
(0.92)\end{array}$ & $\begin{array}{c}314.93^{* *} \\
(3.19) \\
-84.20 \\
(-1.60)\end{array}$ \\
\hline & \multicolumn{4}{|c|}{ SSB before the ban } & \multicolumn{4}{|c|}{ SSB after the ban } \\
\hline Low PC & 45.22 & -99.23 & 87.49 & 101.66 & 398.23 & -98.63 & 70.35 & 0.24 \\
\hline 2 & -148.44 & -14.87 & 68.84 & 52.02 & 94.57 & 107.66 & -52.29 & -75.94 \\
\hline 3 & -68.59 & -189.47 & 118.83 & -29.08 & -8.99 & -12.20 & -306.34 & -327.79 \\
\hline 4 & -118.40 & -332.67 & 109.66 & -147.31 & 92.52 & 37.22 & -243.20 & -198.89 \\
\hline High PC & 122.73 & 109.44 & 189.03 & 129.72 & -197.11 & -17.63 & -322.54 & -182.06 \\
\hline $\begin{array}{c}3-\mathrm{L} \\
t\end{array}$ & $\begin{array}{r}-113.81 \\
(-1.67)\end{array}$ & $\begin{array}{l}-90.24 \\
(-0.55)\end{array}$ & $\begin{array}{l}31.34 \\
(0.50)\end{array}$ & $\begin{array}{c}-130.74 \\
(-1.43)\end{array}$ & $\begin{array}{c}-407.22^{* *} \\
(-2.39)\end{array}$ & $\begin{array}{l}86.43 \\
(0.73)\end{array}$ & $\begin{array}{c}-376.69^{* *} \\
(-2.85)\end{array}$ & $\begin{array}{c}-328.02^{* *} \\
(-2.62)\end{array}$ \\
\hline $\begin{array}{c}\mathrm{H}-3 \\
t\end{array}$ & $\begin{array}{c}191.32^{* *} \\
(3.02)\end{array}$ & $\begin{array}{c}298.91 \\
(1.77)\end{array}$ & $\begin{array}{l}70.21 \\
(1.29)\end{array}$ & $\begin{array}{l}158.80 \\
(1.52)\end{array}$ & $\begin{array}{c}-188.12 \\
(-1.53)\end{array}$ & $\begin{array}{l}-5.43 \\
(-0.05)\end{array}$ & $\begin{array}{l}-16.19 \\
(-0.19)\end{array}$ & $\begin{array}{c}145.72 \\
(2.15)\end{array}$ \\
\hline
\end{tabular}

Quintiles are formed based on open buy put call ratios on day $t$. Returns are in basis points from day $t$ to $t+5$. Raw $\mathrm{E}$. is equal weighted raw returns, Raw $\mathrm{V}$. is value weighted raw returns, Ex. E. is equal weighted excess return adjusted for four risk factors, and Ex. V. is value weighted excess returns. T-stats adjusted for Newey West (1987) serial correlation and heteroskedasticity are in braces. ${ }^{* *}$ : significant at $5 \%$. 
compute each quintile's following five trading day cumulative returns. The first quintile includes stocks with low put/call ratios, and the fifth quintile has stocks with high put call ratios. We report four different measures of returns; equal and value weighted raw returns, and equal and value weighted risk adjusted returns. When constructing the risk-adjusted returns, we use a four-factor model of market, size, value and momentum to remove the systematic component from raw stock returns, and estimate factors betas with daily returns from August 2007 to July 2008.

Consistent with negative information spreading more slowly on stock prices under short sale prohibition, we see that for the SSB stocks during the ban, the high PC quintile has the lowest future returns for all the four different return measures, and the differences between the fifth and the third quintiles are all significantly negative, while the differences between the third and the first quintile are not statistically different from zero. For example, in equal weighted five day raw returns, the high PC quintile underperforms the third quintile by 401.29 basis points ( $t$-stats: -4.45$)$, while the third and the first quintile difference is only 110.23: ( $t$-stats: 0.58$)$. On the contrary, we do not observe the similar pattern for the control stocks during the ban or the SSB stocks during non-ban periods; neither the high put call ratio quintile have the lowest returns, nor return difference between the high and the third quintile is statistically significantly negative.

We then conduct regression analysis to test the asymmetric predictability of option signal using the following specification:

$$
R_{t, t+\tau}^{i}=a+b^{L} P C L_{t}^{i}+b^{H} P C H_{t}^{i}+c \ln \left(\operatorname{size}_{t}^{i}\right)+f R_{t-5, t}^{i}+\epsilon_{t}^{i},
$$


where $R_{t, t+\tau}^{i}$ with $\tau=1,2, \ldots, 5$ is the future $\tau$-day cumulative raw return for stock $i$. We focus on raw returns in our main analysis as it is difficult to measure the risk of each stock during crisis. The results remain similar if we us common risk factor adjusted returns. In Equation 2, $P C L_{t}^{i}$ and $P C H_{t}^{i}$ are proxies for positive and negative information signal, respectively. If stock $i$ is in the low (bottom) put call ratio (PC) quintile on date $t$, we assign $P C L_{t}^{i}$ to be 1 , and zero otherwise. Likewise, if stock $i$ is in the high (top) PC quintile on date $t$, we assign $P C H_{t}^{i}$ to be 1 and zero otherwise. We include market capitalization Size $_{t}^{i}$ as control because size also influence information efficiency and returns. We include stock $i$ 's return from date $t-5$ to date $t$ to control for potential contrarian arising from market illiquidity.

If short sale prohibition does slow down the adjustment of stock prices to negative information and if this negative information is contained in the trading of put options, we expect the coefficient $b^{H}$ to be negative for the sample of SSB stocks during the ban. By contrast, the coefficient $b^{L}$ picks up the positive side of the information content and is less affected by the ban, we expect it to be less significant than $b^{L}$. Moreover, we would expect this asymmetry between $b^{H}$ and $b^{L}$ to present only during the ban period for the SSB stocks. We do not expect to observe the same asymmetric predictability for the control stocks during the ban, or for the SSB sample during non-ban periods. 


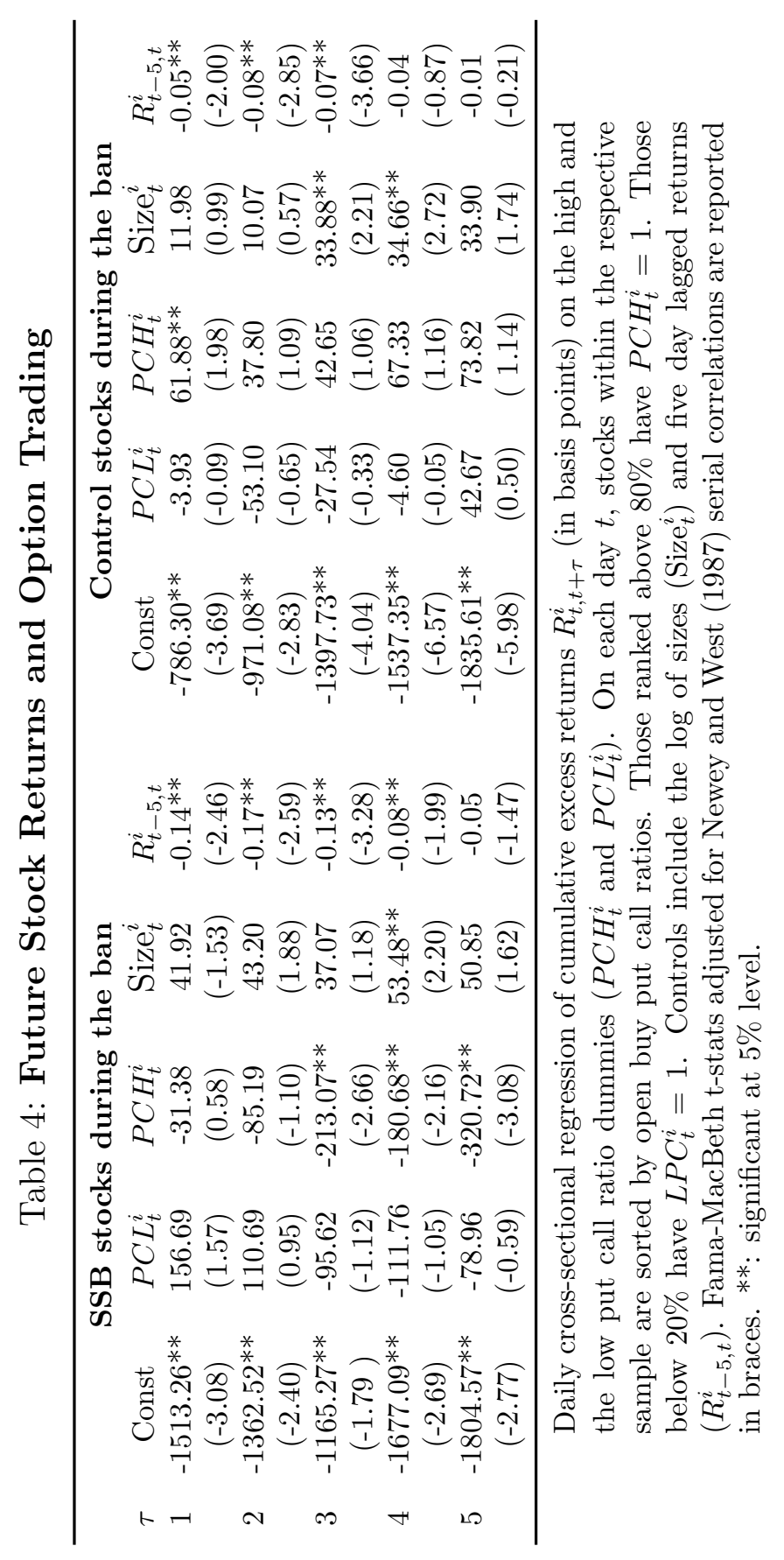


Our results are summarized in Table 4. Indeed, for the sample of SSB stocks during the ban, the slope coefficients on the high put call ratio dummy $(P C H)$ is negative and statistically significant from day 3 to 5 , while the slope coefficient on $P C L$ are mixed in sign and not significantly different from zero. When the dependent variable is future three-day returns, the coefficient estimate on $P C H$ is -213.07 ( $t$-stats:-2.66). When the dependent is future five-day return, the coefficient estimate on $P C H$ is -320.72 ( $t$-stats=-3.08). On the contrary, the estimates on $P C L$ are all not statistically different from zero. This result indicates that relative to the average SSB stocks, those SSB stocks in the top put call ratio quintile underperforms by $2.13 \%$ and $3.21 \%$ over the next three and five business days, respectively. By contrast, the future returns of the SSB stocks with below 20th percentile put call ratios are not different from the average SSB stocks during the ban.

The left Panel of Table 4 reports the result for the control sample during the ban period. We do not find any predictability from put call ratios for future stock returns: neither the coefficient on $P C H$ nor that on the $P C L$ is statistically significant. Table 4 also shows that the coefficient estimates on other independent variables are similar for SSB and control stocks. The estimates on size are positive and the estimates on lagged returns are negative. As a comparison, we also perform the same regression analysis for the SSB stocks over the non-ban periods. Figure 1 reports the $95 \%$ confidence interval of coefficient estimates on $P C H$ and $P C L$ of SSB stocks in different periods. To check if the predicted return reverse, we report the result for up to ten day returns. We can see that the predictability of $P C H$ during the ban do not reverse. Right before and after the ban, $P C H$ and $P C L$ have no information for future stock returns. While, during normal time period (January to July 2008), $P C H$ and $P C L$ have power in predicting returns with similar magnitude. This 

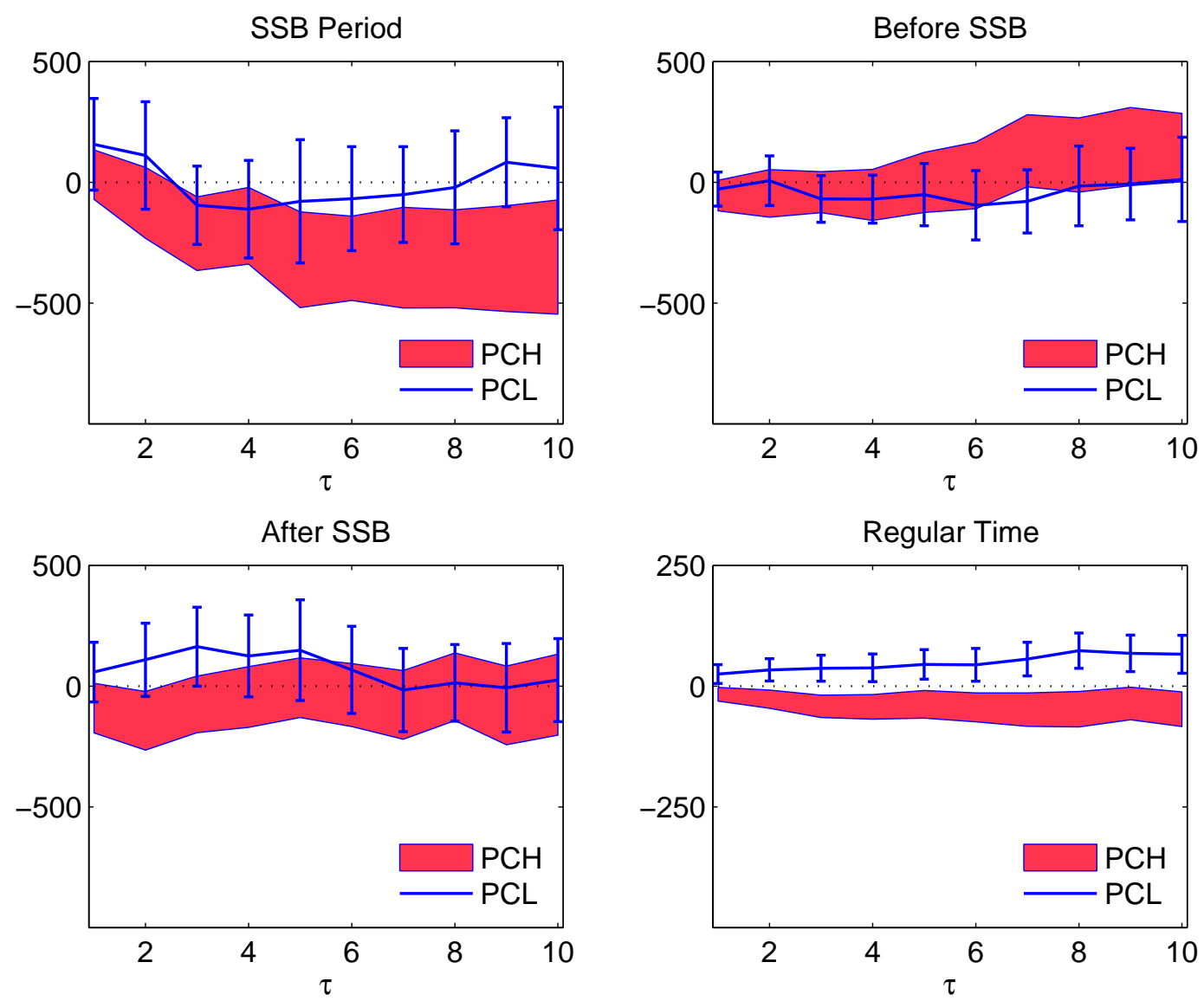

Figure 1: 95\% Confidence Interval of Coefficient Estimates on $P C H$ and $P C L$ for SSB Stocks in Various Periods. The dependents are future 1 day to 10 day cumulative returns. Controls are log sizes and lagged five day returns. 
symmetric predictability patterns of put call ratios during normal time period confirms that under short sale prohibition, stock prices adjust negative information with a delay.

\subsection{Daily Coefficients}

Given that the short sale ban lasts only for 14 trading days, it is possible the asymmetric predictability from put call ratios of SSB stocks is driven by a few extreme observations. We plot the daily coefficient estimates from Fama-Macbeth regression on the high put call ratio dummy $(P C H)$ in Figure 2, where the dependent variables are future five-day returns. We can see that $\mathrm{PCH}$ can predict banned stock returns on most of the trading days during the ban. Thirteen out of fourteen coefficients on $P C H$ are negative. Thus our finding is not driven by a few extreme observations.

It is worthy to note that the only day when $P C H$ has no predictability is the first trading day of the ban, September 19. On that day SEC granted option market maker to sell short until 11:59pm on the same day to facilitate the expiration of options, which suggests that option market makers wouldn't be able to short sale afterwards. ${ }^{8}$ While on early morning of Monday September 22, the second trading day of the ban, the SEC amended the ban and allowed option market maker short sell, in view of option market would not function without short sale by the market makers. ${ }^{9}$ The positive coefficient on $P C H$ on first day of the ban implies that when option market makers are prohibited from short sale, they are unwilling to sell puts to retail investors, and option trading does not contain negative information.

\footnotetext{
${ }^{8}$ See SEC Release 34-58572, September 18,2008.

${ }^{9}$ See 'Options Market Makers Get Relief from SEC Ban on Short-Selling', Traders Magazine Online News, September 22,2008.
} 


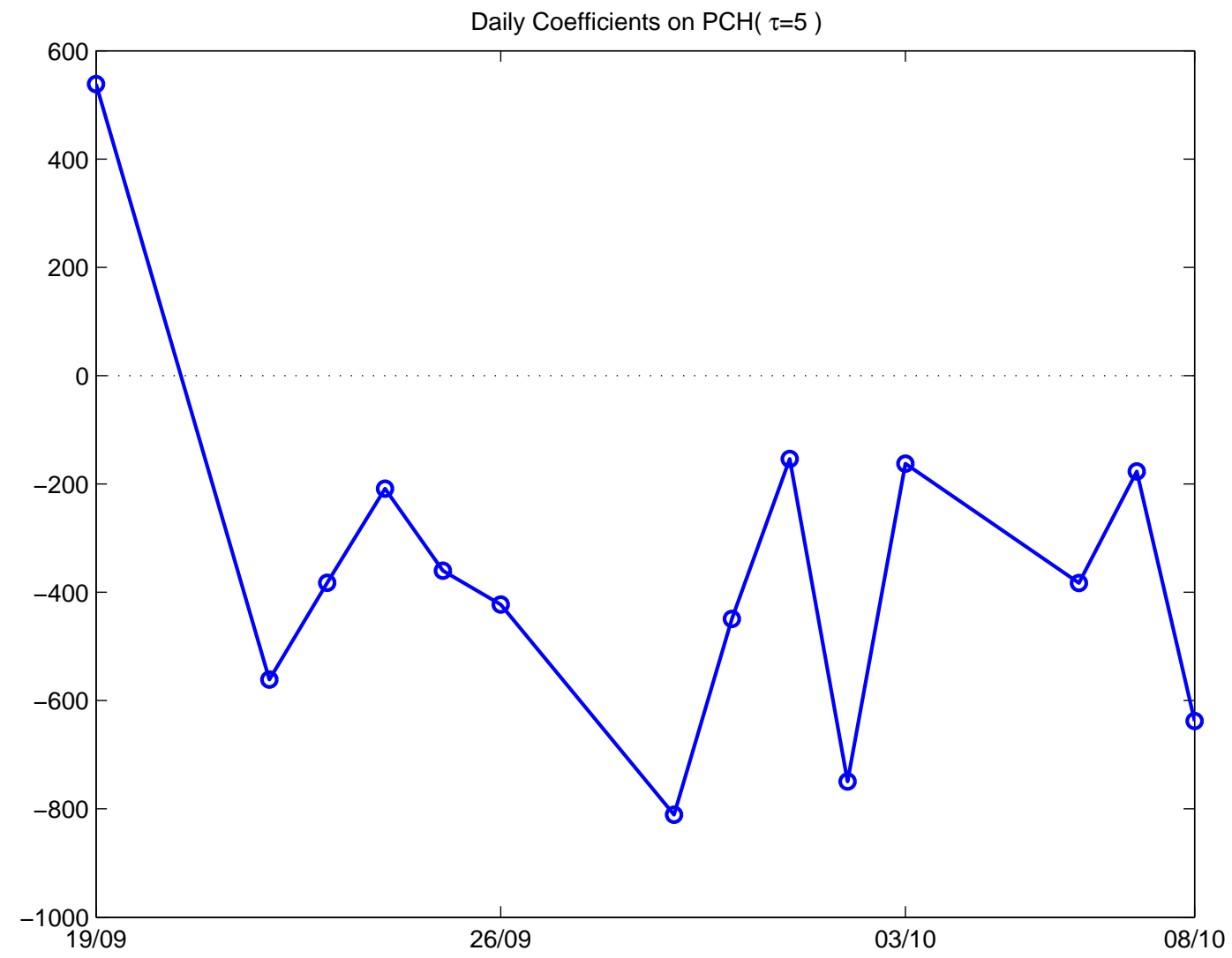

Figure 2: Daily Coefficient Estimates on High Put Call Ratio Dummy $(P C H)$. The dependent is future 5 day cumulative returns. $P C H$ is dummy for stocks ranked above $80 \%$. Other independent variables are low put call ratio dummy, log sizes and lagged five day returns. 


\subsection{Different Trade Sizes}

We now examine the information content of options on the SSB stock by breaking down open buy option volumes into different trade sizes. In CBOE and ISE option data, each type of volume is subdivided into small, large and medium trades. Small trades are orders less than 100 contracts, large trades are orders larger than 199 contracts, and medium trades are in between.

As specified in equation (2), we regress the future stock returns on the high and the low put-call ratio dummies constructed from the open buy volumes of different trade sizes. To generate enough observations for small trades, we include all stock-days with at least one contract of open purchased volume. Figure 3 reports the $95 \%$ confidence interval of coefficient estimates on dummies for SSB stocks in various periods. Similar to the main results, for all three types of trades, prediction only occurs on high put-call ratio dummy (PCH) but not low put-call ratio dummy (PCL) during the ban. PCH from small and large trades provide stronger predictive power than that from medium trades. This is because volume from medium trades only accounts for $10 \%$ of volume initiated by public investors, while the portions from small and large trades are above $40 \%$. Figure 3 also shows that during regular time period, for all three types of trades, PCH and PCL predict stock returns in a symmetric way. 

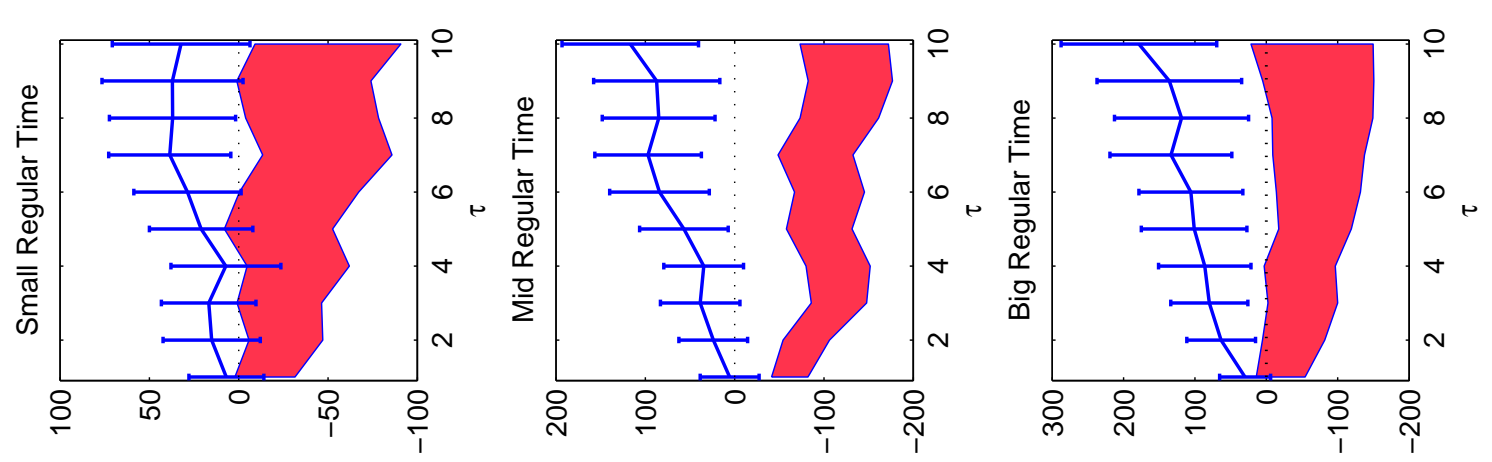

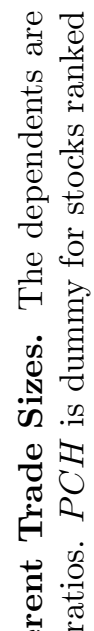
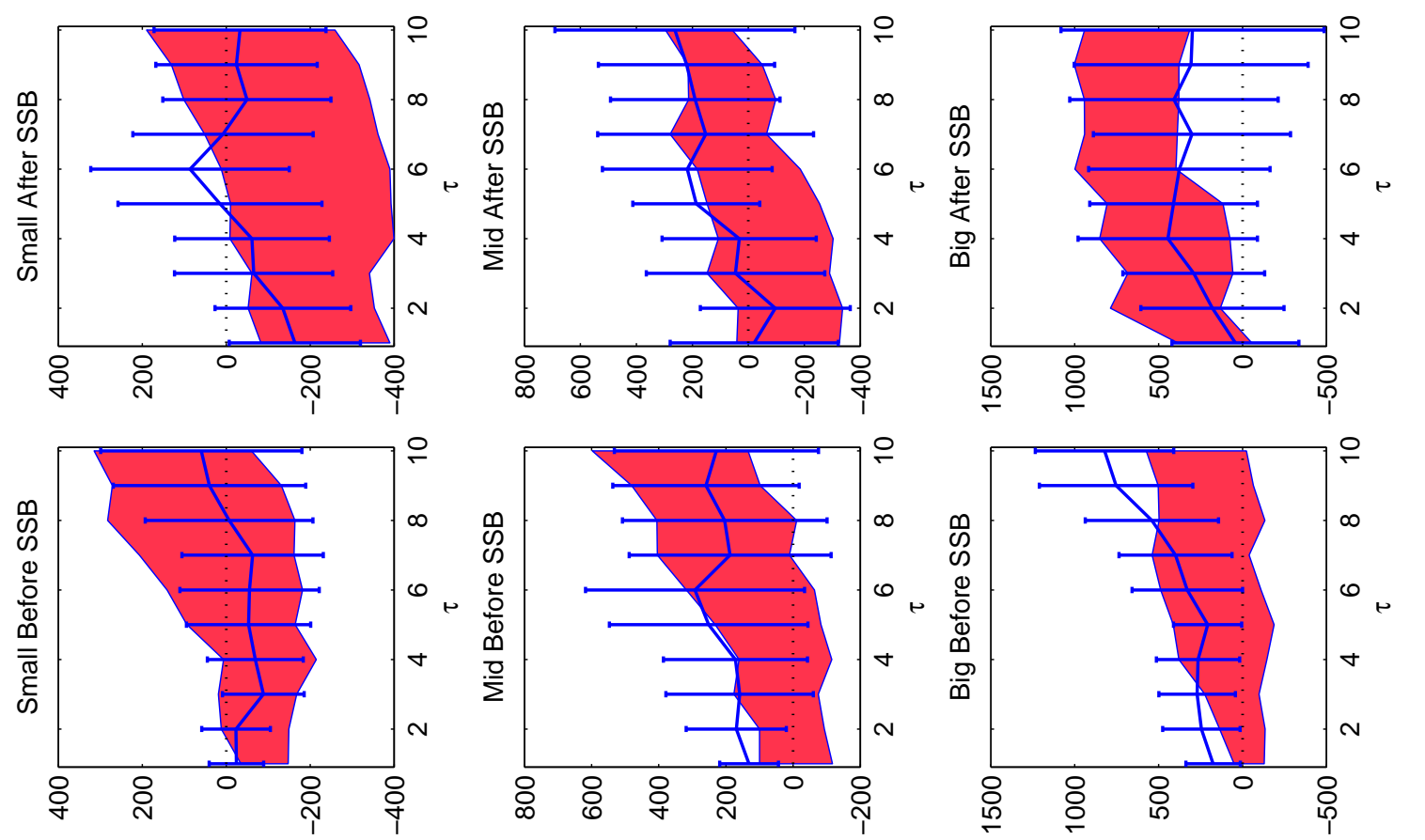

焉

岁芝要

붕

의

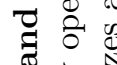

고에

궁

塎 50

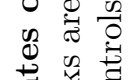
ซु से ह

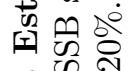
足政 웡 邑 4 .

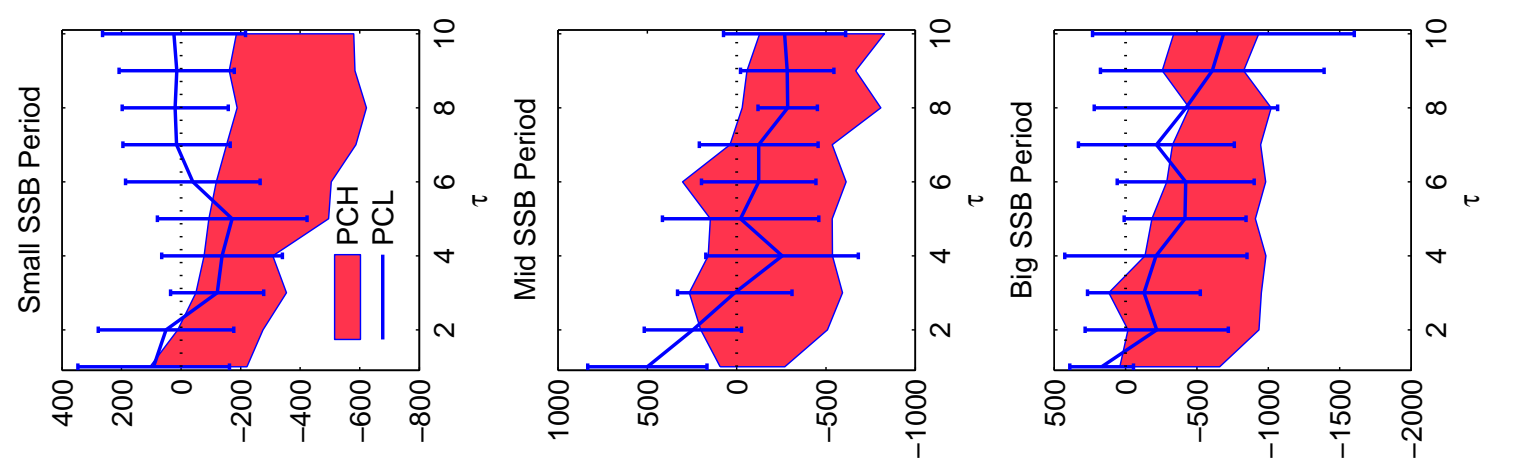

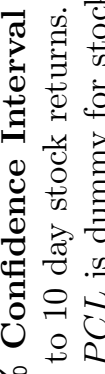
命 的乎 要

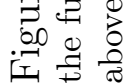




\section{CDS and future stock returns}

During the ban, investors in CDS market can still buy CDS to profit on negative information. Given that CDS is an insurance on the default of a firm, it is naturally more sensitive to negative information, making it a good candidate for our analysis. Cross-sectionally, a firm with more positive change in CDS is the one with more negative information. If short sale ban reduces the speed of the stock price adjustment to negative information and trading impacts CDS spread as documented in Tang and Yan (2011), we expect an increase in CDS would predict a low future stock return. To test this predictability we use the following regression model:

$$
R_{t, t+\tau}^{i}=a+b \Delta C D S_{t}^{i}+c \ln \left(\operatorname{size}_{t}^{i}\right)+d R_{t-5, t}^{i}+\epsilon_{t}^{i},
$$

$$
\text { where } \Delta C D S_{t}^{i}=100 \% \mathrm{x}\left(C D S_{t}^{i}-C D S_{t-1}^{i}\right) / C D S_{t-1}^{i} \text {, }
$$

where $R_{t, t+\tau}^{i}$ is the cumulative return of stock $i$ from trade day $t$ to $t+\tau, \Delta C D S_{t}^{i}$ is the percentage change of CDS from date $t-1$ to date $t, R_{t-5, t}^{i}$ is past five day return. If short sale ban slows down the stock price adjustment to negative information, the coefficient on $\triangle C D S_{t}^{i}$ will be negative for the SSB stocks during the ban, but not different from zero for the control stocks during the ban or SSB stocks during the non-ban periods.

The result presents in Table 5 shows that the coefficient estimates on $\triangle C D S$ are negative and statistically significant only for the SSB stocks during the ban. When the dependent variable is two (five) day future returns, the coefficient estimate is -11.53 (-24.07), implying a one standard deviation increase in $\triangle C D S$ is associated with $1.29 \%(2.69 \%)$ return decrease 
Table 5: Future Stock Returns and Percentage Changes of CDS

\begin{tabular}{|c|c|c|c|c|c|c|c|c|}
\hline \multicolumn{9}{|c|}{ Panel A. The SSB and control stocks during the ban } \\
\hline & \multicolumn{4}{|c|}{ SSB stocks } & \multicolumn{4}{|c|}{ Control stocks } \\
\hline$\tau$ & const & $\Delta C D S_{t}^{i}$ & $\operatorname{Size}_{t}^{i}$ & $R_{t-5, t}^{i}$ & const & $\Delta C D S_{t}^{i}$ & $\operatorname{Size}_{t}^{i}$ & $R_{t-5, t}^{i}$ \\
\hline 1 & $\begin{array}{c}-1171.27^{* *} \\
(-2.59)\end{array}$ & $\begin{array}{c}-8.90^{* *} \\
(-1.89)\end{array}$ & $\begin{array}{l}48.05 \\
(1.73)\end{array}$ & $\begin{array}{c}-0.12^{* * *} \\
(-2.25)\end{array}$ & $\begin{array}{c}-574.05^{* *} \\
(-2.48)\end{array}$ & $\begin{array}{c}0.92 \\
(1.48)\end{array}$ & $\begin{array}{c}22.56^{* *} \\
(2.35)\end{array}$ & $\begin{array}{c}-0.01 \\
(-0.25)\end{array}$ \\
\hline 2 & $\begin{array}{c}-1622.90^{* *} \\
(-3.86)\end{array}$ & $\begin{array}{c}-11.53^{* *} \\
(-2.61)\end{array}$ & $\begin{array}{c}58.39^{* *} \\
(2.05)\end{array}$ & $\begin{array}{c}-0.15^{* *} \\
(-2.18)\end{array}$ & $\begin{array}{c}-850.10^{* *} \\
(-2.26)\end{array}$ & $\begin{array}{c}1.18 \\
(0.90)\end{array}$ & $\begin{array}{l}27.51 \\
(1.84)\end{array}$ & $\begin{array}{c}-0.04 \\
(-0.92)\end{array}$ \\
\hline 3 & $\begin{array}{c}-2056.30^{* *} \\
(-5.40)\end{array}$ & $\begin{array}{c}-19.34^{* *} \\
(-1.96)\end{array}$ & $\begin{array}{c}71.59^{* *} \\
(2.27)\end{array}$ & $\begin{array}{c}-0.14^{* *} \\
(-2.47)\end{array}$ & $\begin{array}{c}-1169.61^{* *} \\
(-2.81)\end{array}$ & $\begin{array}{c}2.12 \\
(1.09)\end{array}$ & $\begin{array}{c}37.99^{* * *} \\
(2.41)\end{array}$ & $\begin{array}{r}-0.06 \\
(-1.29)\end{array}$ \\
\hline 4 & $\begin{array}{c}-2247.7^{* *} 6 \\
(-4.57)\end{array}$ & $\begin{array}{c}-24.41^{* *} \\
(-1.91)\end{array}$ & $\begin{array}{c}78.75^{* *} \\
(2.75)\end{array}$ & $\begin{array}{c}-0.12^{* *} \\
(-2.04)\end{array}$ & $\begin{array}{c}-1484.21^{* *} \\
(-2.37)\end{array}$ & $\begin{array}{l}1.20 \\
(0.49)\end{array}$ & $\begin{array}{c}49.14^{* *} \\
(2.06)\end{array}$ & $\begin{array}{c}-0.04 \\
(-0.70)\end{array}$ \\
\hline 5 & $\begin{array}{c}-2679.22^{* *} \\
(-5.39)\end{array}$ & $\begin{array}{c}-24.07^{* *} \\
(-2.01)\end{array}$ & $\begin{array}{l}92.1^{* *} \\
(2.92)\end{array}$ & $\begin{array}{l}-0.07 \\
(-1.44)\end{array}$ & $\begin{array}{c}-1788.24^{* *} \\
(-3.92)\end{array}$ & $\begin{array}{c}1.34 \\
(0.56)\end{array}$ & $\begin{array}{c}56.58^{* *} \\
(2.25)\end{array}$ & $\begin{array}{l}-0.07 \\
(-0.98)\end{array}$ \\
\hline \multicolumn{9}{|c|}{ Panel B. The SSB stocks during non-ban periods } \\
\hline \multicolumn{4}{|c|}{ Before Ban } & \multicolumn{2}{|c|}{ After Ban } & \multicolumn{3}{|c|}{ Regular Time } \\
\hline \multirow{2}{*}{$\begin{array}{l}\tau \\
1\end{array}$} & \multicolumn{3}{|c|}{$\triangle C D S_{t}^{i}$} & \multicolumn{2}{|c|}{$\Delta C D S_{t}^{i}$} & \multicolumn{3}{|c|}{$\Delta C D S_{t}^{i}$} \\
\hline & \multicolumn{3}{|c|}{$\begin{array}{l}-5.81 \\
(-1.64)\end{array}$} & \multicolumn{2}{|c|}{$\begin{array}{c}0.41 \\
(0.10)\end{array}$} & \multicolumn{3}{|c|}{$\begin{array}{l}-1.52 \\
(-1.29)\end{array}$} \\
\hline 2 & \multicolumn{3}{|c|}{$\begin{array}{l}-8.79 \\
(-1.49)\end{array}$} & \multicolumn{2}{|c|}{$\begin{array}{c}4.21 \\
(0.92)\end{array}$} & \multicolumn{3}{|c|}{$\begin{array}{l}-1.98 \\
(-1.40)\end{array}$} \\
\hline 3 & \multicolumn{3}{|c|}{$\begin{array}{l}-5.92 \\
(-0.57)\end{array}$} & \multicolumn{2}{|c|}{$\begin{array}{c}7.82 \\
(1.10)\end{array}$} & \multicolumn{3}{|c|}{$\begin{array}{l}-1.26 \\
(-0.69)\end{array}$} \\
\hline 4 & \multicolumn{3}{|c|}{$\begin{array}{l}-10.37 \\
(-0.87)\end{array}$} & \multicolumn{2}{|c|}{$\begin{array}{c}5.71 \\
(0.75)\end{array}$} & \multicolumn{3}{|c|}{$\begin{array}{l}-1.98 \\
(-0.96)\end{array}$} \\
\hline 5 & \multicolumn{3}{|c|}{$\begin{array}{l}-8.19 \\
(-0.65)\end{array}$} & \multicolumn{2}{|c|}{$\begin{array}{c}4.38 \\
(0.68)\end{array}$} & \multicolumn{3}{|c|}{$\begin{array}{l}-1.33 \\
(-0.76)\end{array}$} \\
\hline
\end{tabular}

Daily cross-sectional regression of cumulative returns $R_{t, t+\tau}^{i}$ on daily CDS percentage change $\left(\Delta C D S_{t}^{i}\right)$. Returns are in basis points. Controls include the log of sizes $\left(\operatorname{Size}_{t}^{i}\right)$ and lagged five day returns $\left(R_{t-5, t-1}^{i}\right)$. Coefficient estimates on controls are omitted in Panel B. Fama-MacBeth t-stats adjusted for Newey and West (1987) serial correlations are reported in braces. ${ }^{* *}$ : significant at $5 \%$ level. 
in next two (five) days. While for the control stocks, the coefficient estimates on $\triangle C D S$ are not significantly different from zero. Panel B of Table 5 reports the coefficient estimates on $\triangle C D S$ for the SSB stocks during the non-ban periods. To save space we omit the estimates on the constant and control variables. As shown in Panel B, the CDS has no predictability during non-ban periods. Right before the ban and during the normal time period from January to July 2008 , the coefficients on $\triangle C D S$ are negative without statistical significance, and during the post ban period, the coefficients are positive and not significant.

If short sale ban impedes stock prices from incorporating negative information but not positive information, we expect only increases of CDS during the ban would predict low stock returns, and decreases of CDS would not be related to high subsequent stock returns. To test this asymmetric predictability hypothesis we use following specification:

$$
R_{t, t+\tau}^{i}=a+b \Delta C D S_{t}^{i}+c \Delta C D S_{t}^{i} H_{t}^{i}+d H_{t}^{i}+f \ln \left(\operatorname{size}_{t}^{i}\right)+f R_{t-5, t}^{i}+\epsilon_{t}^{i},
$$

where $H_{t}^{i}$ is the high CDS change dummy; it is one for company $i$ on day $t$ if its $\triangle C D S_{t}^{i}$ is above median on day $t$. If the predictability of $\triangle C D S$ is asymmetric for the SSB stocks during the ban, the coefficient on the interaction term between $\triangle C D S$ and $H$ will be negative, and the predictability of $\triangle C D S$ in equation (5) will be weaker than that in equation (3).

As shown in Table 6 , the coefficient estimates on the interaction term between $\triangle C D S$ and $H$ are all negative and statistically significant. After adding the interaction term, $\triangle C D S$ no longer has predictability for the SSB stock returns. For example, when the dependent variable is two day future returns, the coefficient estimate on the interaction term is -54.39 (t-stats: -2.09), while the estimate on $\triangle C D S$ is 20.84 (t-stats: 1.29). These numbers indicate 
that the predictability of CDS during the ban is driven by the SSB stocks with high increases in CDS but not those with low or negative increases in CDS. This result is consistent with that short sale ban reduces the speed of stock price adjustment to negative information.

Table 6: Future Stock Returns and High Percentage Changes of CDS

\begin{tabular}{ccccccc}
\hline \multicolumn{7}{c}{ The SSB Stocks during the Ban } \\
$\tau$ & const & $\Delta C D S_{t}^{i}$ & $\Delta C D S_{t}^{i} H_{t}^{i}$ & $H_{t}^{i}$ & Size $_{t}^{i}$ & $R_{t-5, t}^{i}$ \\
1 & $-1097.41^{* *}$ & 19.55 & $-40.96^{* *}$ & 55.17 & $44.39^{* *}$ & $-0.12^{* *}$ \\
& $(-2.33)$ & $(1.67)$ & $(-2.84)$ & $(0.83)$ & $(1.91)$ & $(-2.11)$ \\
2 & $-1456.01^{* *}$ & 20.84 & $-54.39^{* *}$ & -15.04 & $52.56^{* *}$ & $-0.14^{* *}$ \\
& $(-3.43)$ & $(1.29)$ & $(-2.06)$ & $(-0.18)$ & $(2.52)$ & $(-1.94)$ \\
3 & $-1959.63^{* *}$ & 18.25 & $-64.67^{* *}$ & 77.81 & $66.31^{* *}$ & $-0.13^{* *}$ \\
& $(-4.81)$ & $(1.16)$ & $(-3.59)$ & $(1.01)$ & $(2.59)$ & $(-2.42)$ \\
4 & $-2360.47^{* *}$ & 18.25 & $-54.99^{* *}$ & 69.43 & $87.40^{* *}$ & $-0.16^{* *}$ \\
& $(-4.50)^{* *}$ & $(0.74)$ & $(-2.14)$ & $(0.64)$ & $(3.30)$ & $(-2.07)$ \\
5 & $-2654.81^{* *}$ & 14.51 & $-68.61^{* *}$ & -60.51 & $99.04^{* *}$ & -0.07 \\
& $(-4.52)$ & $(0.52)$ & $(-2.13)$ & $(-0.48)$ & $(3.11)$ & $(-1.40)$ \\
\hline
\end{tabular}

Daily cross-sectional regression of cumulative returns $R_{t, t+\tau}^{i}$ on CDS percentage change $\left(\Delta C D S_{t}^{i}\right)$, and its intersection with high CDS change dummy $\left(H_{t}^{i}\right)$. Returns are in basis points. On each day $t$, SSB stocks with above median $\triangle C D S_{t}^{i}$ have $H_{t}^{i}=1$, zero otherwise. Controls include the log of equity sizes $\left(\operatorname{Size}_{t}^{i}\right)$ and the lagged returns $\left(R_{t-5, t}^{i}\right)$. Fama-MacBeth t-stats adjusted for Newey and West (1987) serial correlations are reported in squared brackets. **: significant at $5 \%$ level.

\section{Conclusions}

In this paper, we focused on the short sale ban of 2008 and examined the interaction between price discovery in banned stocks and the trading of options and CDS during the 14-day period. We found that in the presence of short sale ban, it takes time for the negative information contained in either the options market or the CDS market to get incorporated into stock prices.

Given the volatile nature of the markets during the short sale ban, it is important for us to minimize the influence of the overall market movement on our predictive results. For 
this reason, we structured our test to focus within the group of stocks with the same short sale ban and examine the predictability cross-sectionally within this group. In other words, our finding of sluggishness in price impoundment is a measure of one banned stock relative to another banned stock. The only thing differentiating one from another is the fact that it has some negative information according to the options market or the CDS market.

In extracting the information from options market, we chose to use the trading information instead of prices, since we would like to capture more of an action variable. Given the volatile nature of the time period and the large bid/ask spreads in the options market, this action variable could perhaps capture option information in a cleaner way. In extracting the information from the CDS market, we could only use the CDS price since trading information was not available. This differing information content has some interesting implications. While our result shows that it takes time for the negative information expressed in the options market to get incorporated into stock prices, our paper is silent on whether or not this information has already been incorporated in the option prices. By using the CDS price data, however, our paper does show that, in the presence of short sale ban, it takes time for the negative information already incorporated in CDS prices to get into stock prices.

Finally, although our original idea was as simple as following the flow of information, our result is a confirmation of the theory prediction of Diamond and Verrecchia (1987). In particular, our result shows that the sluggishness in price impoundment is asymmetric: the information collected from either the options market or the CDS market has predictability only on the negative side, not on the positive side. Moreover, this predictability was not present for the periods immediately before and after the short sale ban, nor was it present for a matching sample of stocks that were not banned. 


\section{References}

Acharya, V. V. and T. C. Johnson (2007). Insider trading in credit derivatives. Journal of Financial Economics.

Aitken, M. J., A. Frino, M. S. McCorry, and P. L. Swan (1998). Short Sales are Almost Instantaneously Bad News: Evidence from the Australian Stock Exchange. Journal of Finance 53, 2205-2223.

Asquith, P. and L. Meulbroek (1996). An Empirical Investigation of Short Interest. Working Paper, Harvard University.

Battalio, R. and P. Schultz (2010). Regulatory Uncertainty and Market Liquidity: The 2008 Short Sale Ban's Impact on Equity Option Markets. Journal of Finance, forthcoming.

Boehmer, E., C. Jones, and X. Zhang (2009). Shackling Short Sellers: The 2008 Shorting Ban. Working Paper, University of Oregon and Columbia Business School and Cornell University.

Boehmer, E., C. M. Jones, and X. Zhang (2008). Which Shorts are Informed? Journal of Finance 63, 491-528.

Boehmer, E., B. Jordan, and Z. Huszar (2010). The Good News in Short Interest. Journal of Financial Economics 96, 80-97.

Bri, A., W. N. Goetzmann, and N. Zhu (2007). Efficiency and the Bear: Short Sales and Markets around the World. Journal of Finance 62, 1029-1079.

Chang, E. C., J. W. Cheng, and Y. Yu (2007). Short-Sales Constraints and Price Discovery: Evidence from the Hong Kong Market. Journal of Finance 62, 2097-2121.

Chen, J., H. Hong, and J. C. Stein (2002). Breadth of Ownership and Stock Returns. Journal of Financial Economics 66, 171-205.

Danielsen, B. and S. Sorescu (2001). Why Do Option Introductions Depress Stock Prices? An Empirical Study of Diminishing Short-Sale Constraints. Journal of Financial and Quantitative Analysis 36, 451-484.

DAvolio, G. (2002). The Market for Borrowing Stock. Journal of Financial Economics 66, $271-306$.

Desai, H., K. Ramesh, S. R. Thiagarajan, and B. V. Balachandran (2002). An Investigation of the Informational Role of Short Interest in the Nasdaq Market. Journal of Finance 5\%, 2263-2287.

Diamond, D. W. and R. E. Verrecchia (1987). Constraints on Short-Selling and Asset Price Adjustment to Private Information. Journal of Financial Economics 18, 277-311.

Diether, K. B., K.-H. Lee, and I. M. Werner (2009). Short-sale Strategies and Return Predictability. Review of Financial Studies 22, 575-607. 
Easley, D., M. O'Hara, and P. Srinivas (1998). Option Volume and Stock Prices: Evidence on Where Informed Traders Trade. Journal of Finance 53, 431-465.

Gagnon, L. and J. Witmer (2009). Short Changed? The Market's Reaction to the Short Sale Ban of 2008. Working Paper, Queen's University.

Geczy, C. C., D. K. Musto, and A. V. Reed (2002). Stocks are Special too: an Analysis of the Equity Lending Market. Journal of Financial Economics 66, 241-269.

Han, B. and Y. Zhou (2010). Term Structure of Credit Default Swap Spreads and Cross Section of Stock Returns. Working Paper, University of Texas at Austina and University of Oklahoma.

Harris, L., E. Namvar, and B. Phillips (2009). Price Inflation and Wealth Transfer During the 2008 SEC Short-Sale Ban. Working Paper, University of Southern California.

Jones, C. M. and O. A. Lamont (2002). Short-sale Constraints and Stock Returns. Journal of Financial Economics 66, 207-239.

Kolasinski, A., A. Reed, and J. Thornock (2009). Can Short Restrictions Result in More Informed Short Selling? Evidence from the 2008 Regulations. Working Paper, University of North Carolina.

Longstaff, F. A., S. Mithal, and E. Neis (2005). Corporate Yield Spreads: Default Risk or Liquidity? Journal of Finance 60.

Mayhew, S. and V. Mihov (2005). Short Sale Constraints, Overvaluation, and the Introduction of Options. Working Paper, SEC and Texas Christian University.

Miller, E. (1977). Risk, Uncertainty, and Divergence of Opinion. Journal of Finance 32, 1151-1168.

Newey, W. K. and K. D. West (1987). A Simple Positive Semi-definite, Heteroskedasticity and Autocorrelation Consistent Covariance Matrix Estimator. Econometrica 55, 703708.

Norden, L. and M. Weber (2009). The Co-Movement of credit default swap, bond and stock markets: an empirical analysis. European Financial Management 15, 529-562.

Ofek, E., M. Richardson, and R. F. Whitelaw (2004). Limited Arbitrage and Short Sales Restrictions: Evidence from the Options Markets. Journal of Financial Economics 74, $305-342$.

Pan, J. and A. Poteshman (2006). The Information in Option Volume for Future Stock Prices. Review of Financial Studies 19, 871-908.

Sorescu, S. (2000). The Effect of Options on Stock Prices: 1973 to 1995. Journal of Finance 55, 487-514.

Tang, D. and H. Yan (2011). Price Impact of CDS Trading. Working Paper, Hong Kong University and University of South Carolina. 